\title{
CDK4 has the ability to regulate Aurora B and Cenpp expression in mouse keratinocytes
}

\author{
SUNG HYUN LEE ${ }^{1}$, LILIANA R.L. RODRIGUEZ ${ }^{2}$, RIMA MAJUMDAR ${ }^{1}$, \\ PAULA L. MILIANI DE MARVAL ${ }^{3}$ and MARCELO L. RODRIGUEZ-PUEBLA ${ }^{1}$ \\ ${ }^{1}$ Department of Molecular Biomedical Sciences, Center for Human Health and The Environment, \\ North Carolina State University, Raleigh, NC 27607, USA; ${ }^{2}$ Department of Clinical Analysis, General Acute Hospital, \\ Parmenio Piñeiro, Buenos Aires 1406, Argentina; ${ }^{3}$ Charles River Laboratories, Inc., Morrisville, NC 27560, USA
}

Received February 5, 2021; Accepted July 16, 2021

DOI: 10.3892/ol.2021.12993

\begin{abstract}
Cyclin-dependent kinase 4 (CDK4) is a critical molecule that regulates key aspects of cell proliferation through phosphorylation of the retinoblastoma $(\mathrm{Rb})$ family of proteins. In the last few years, it has been suggested that CDK4 plays alternative roles in cell proliferation and tumorigenesis. The main aim of the present study was to define a novel CDK4 function as a transcriptional regulator of genes involved in chromosome segregation, contributing to the $\mathrm{G}_{2} / \mathrm{M}$ phase transition. Herein, chromatin-immunoprecipitation reverse transcription-quantitative PCR assays were performed to demonstrate that CDK4 could occupy the promoter region of genes associated with chromosomal segregation, such as Aurora-B (Aurkb) and Centromere Protein P (CENP-P). Moreover, gain- and loss-of-function experiments showed that CDK4 participated in the transcriptional regulation of Aurkb and CENP-P. The finding that Aurkb may have a crucial role in chromosome bi-orientation and the spindle assembly checkpoint, and that CENP-P could be required for proper kinetochore function suggests that dysregulation of CDK4 expression induces chromosomal instability and, in some cases, cancer development.
\end{abstract}

\section{Introduction}

Progress from $G_{0}$ to $G_{1}$ and through the $G_{1}$ phase of the mammalian cell cycle is mediated by the cyclin-dependent

Correspondence to: Dr Marcelo L. Rodriguez-Puebla, Department of Molecular Biomedical Sciences, Center for Human Health and The Environment, North Carolina State University, 1060 William Moore Drive, Raleigh, NC 27607, USA

E-mail: mrodriguez@ncsu.edu

Abbreviations: CDK4, cyclin-dependent kinase 4; CIN, chromosome instability; ChIP, chromatin immunoprecipitation

Key words: cell-cycle, cyclin-dependent kinase 4, Aurora-B, Centromere Protein P, skin, keratinocytes kinases 4 and 6 (CDK4, CDK6), which are activated through binding with their regulatory subunits D-type cyclins (D1, D2, and D3) (1-4). It is widely accepted that CDK4 regulates critical aspects of the cell cycle via phosphorylation of the retinoblastoma $(\mathrm{Rb})$ family of proteins $(5,6)$. Thus, the so-called CDK4/6- $\mathrm{Rb}$ axis is considered essential to cell-cycle entry and progression. Although this canonical role of CDK4 as a driver of cell proliferation has been firmly established, research carried out over the last few years has suggested cell cycle-independent functions of CDKs and D-type cyclins $(7,8)$. For example, a novel role for CDK6 in hematopoietic cells that exceeds its function as a cell-cycle regulator has been recognized (9). Increasing evidence suggests that cyclin D1 carries out essential functions in other processes such as transcription and DNA damage $(7,10,11)$.

Interestingly, a systematic screen has defined other potential substrates for CDK4, including the transcription factor forkhead box protein M1 (FOXM1) (12). Our skin carcinogenesis studies also suggested that CDK4 plays additional roles unrelated to its canonical function in the CDK-Rb axis. We reported that transgenic expression of CDK4 in mouse epidermis favors the malignant progression of skin tumors (13). However, forced expression of the other $\mathrm{G}_{1}$-CDKs, such as CDK6 and CDK2, in mouse keratinocytes resulted in elevated $\mathrm{Rb}$ phosphorylation but did not induce malignant progression such as observed in CDK4 transgenic mice $(14,15)$. Moreover, a putative role of CDK4 in chromosome instability, and consequently in malignant progression, was reported by Adon et al, in which the absence of CDK4 or CDK2 prevents centrosome amplification (16).

Herein we report a novel function of CDK4 regulating the transcriptional expression of genes involved in chromosome segregation. Chromatin-immunoprecipitation (ChIP) analysis shows that CDK4 occupies the promoter of genes associated with chromosomal segregation, such as Aurkb (Aurora-B) and CENP-P (Centromere Protein P). Gain- and loss-of-function experiments showed that CDK4 participates in the transcriptional regulation of $A u r k B$ and $C E N P$ - $P$ promoters. Importantly, Aurora-B is a subunit of the chromosome passenger complex controlling several aspects of chromosome segregation (17). Thus, deregulation of Aurora-B through CDK4 expression would result in a malfunction of the chromosome segregation 
events and potentially tumorigenesis (18). Our results suggest that CDK4 may contribute to $\mathrm{G}_{2} / \mathrm{M}$ regulation in addition to the prominent role in $\mathrm{G}_{0} / \mathrm{G}_{1}$ - and $\mathrm{G}_{1} / \mathrm{S}$-transitions. Aurora-B expression peaks during mitosis have a crucial role in chromosome bi-orientation and the spindle-assembly checkpoint, whereas CENP-P is required for proper kinetochore function $(19,20)$, suggests that CDK4 plays a pivotal role in maintaining chromosomal stability.

\section{Materials and methods}

Cell lines and primary mouse keratinocytes. The 308-cell line was acquired through a previous research collaboration with Dr. Claudio Conti (MD Anderson Cancer Center, Texas). This immortalized cell line was derived from calcium-resistant foci of keratinocytes from adult Balb/c mouse initiated by 7,12-dimethylbenz[a]anthracene and has been extensively used as a model of cell proliferative (21-23). NIH3T3 murine embryo fibroblasts cell line was obtained from the American Type Culture Collection (Catalog number CRL-1658; ATCC). Primary keratinocytes were isolated from newborn mice and cultured in a low $\mathrm{Ca}^{+}$medium (EMEM, 06-174 G; Cambrex-bioz) as described previously (24). Briefly, four newborns of $48 \mathrm{~h}$ of age were washed with ethanol and iodine solution and put in the refrigerator $\left(4^{\circ} \mathrm{C}\right)$ for $30 \mathrm{~min}$ to induce hypothermic anesthesia. After anesthesia by refrigeration, the newborns were euthanized by decapitation, and skin was removed with forceps, rinsed, and continue with the cell culture process $(24,25)$. The generation of mouse primary keratinocytes and protocols for animal use were approved for the North Carolina State University Institutional Animal Care and Use Committee (IACUC) protocol number 18-102-B, as required by federal regulations.

Cell extraction and immunofluorescence analysis. To visualize chromatin-bound proteins, unbound nuclear and cytosolic proteins from keratinocyte cell line 308 and primary culture of mouse keratinocytes were removed with cytoskeletal extraction buffer (CSK buffer). 70-80\% confluent 308 cells were grown on coverslips coated with poly-L-lysine (Sigma-Aldrich; Merck KGaA). For CSK extraction, cells were washed with DPBS (Mediatech Inc.) twice and incubated with CSK buffer [100 mM NaCl, $300 \mathrm{mM}$ sucrose, $3 \mathrm{mM} \mathrm{MgCl}{ }_{2}$, $10 \mathrm{mM}$ PIPES (pH.8), and $0.5 \%$ Triton X-100] containing $1 \mathrm{x}$ protease inhibitor cocktail (Sigma-Aldrich; Merck KGaA) for $2 \mathrm{~min}$ on ice. After extraction, cells were fixed in $10 \%$ formalin for 20 min at RT. For DNase extraction, cells permeabilized with CSK buffer were washed with DPBS twice and incubated with 10 units of Optizyme Recombinant DNase I (Thermo Fisher Scientific Inc.) $30 \mathrm{~min}$ at $37^{\circ} \mathrm{C}$ followed by fixation with $10 \%$ formalin.

Immunofluorescence staining cells were blocked with $10 \%$ goat serum diluted in $0.01 \%$ Triton X-100/PBS solution for $30 \mathrm{~min}$ at RT, incubated with primary antibodies against CDK4 (C-22), and HDAC1 (10E2) (Santa Cruz Biotechnology, Inc.) at $4^{\circ} \mathrm{C}$ overnight. Cells were washed with PBS four times and incubated with goat anti-rabbit-FITC conjugated antibody for CDK4 staining (Thermo Fisher Scientific Inc.; Pierce Biotechnology Inc.), and goat anti-mouse-Alexa Fluor 488 (Thermo Fisher Scientific Inc.; Molecular Probes) for HDAC1 staining. DAPI staining was utilized for counterstained (Vector Laboratories Inc.). Cells were examined under a Nikon Eclipse E400 fluorescence microscope (Nikon Corporation), and images were collected with Qcapture software (QImaging).

Retroviral infection and generation of stable cell lines. Murine CDK4 cDNA was subcloned into the pLPCX retroviral vector (Clontech Laboratories, Inc.) using primers containing NotI restriction sites. pLPCX-Cdk4 and pLPCX (empty plasmid) vectors were amplified in DH5 $\alpha$ competent $E$. coli cells (Invitrogen; Thermo Fisher Scientific Inc.). The retroviral vector was transfected into the Platinum Retroviral Packaging Cell line (Plat-E cell) with psPAX2 packing vector (Addgene) using FuGENE ${ }^{\circledR} 6$ Transfection Reagent (Promega Corp.). After $48 \mathrm{~h}$ of transfection, the virus-containing medium was filtered through a $0.45 \mu \mathrm{m}$ of syringe filter (Corning Inc.). Harvested CDK4-retroviruses and control-retrovirus were utilized to infected NIH3T3 and 308 cells with $4 \mu \mathrm{g} / \mathrm{ml}$ of hexadimethrine bromide (polybrene; Sigma-Aldrich;) and incubated overnight. The pLPCX-Cdk4 and pLPCX-empty retrovirus infected cells (NIH3T3-CDK4 and 308-CDK4) were selected with $2 \mu \mathrm{g} / \mathrm{ml}$ of puromycin (Sigma-Aldrich Co. LLC, MO).

Western blot assays. NIH3T3 and 308 cell lines were lysed in RIPA buffer [150 mM NaCl, $1 \%$ NP-40, $0.5 \%$ sodium deoxycholate, $0.1 \%$ SDS, $50 \mathrm{mM}$ Tris- $\mathrm{HCl}(\mathrm{pH} 8.0)]$ containing 1x protease inhibitor cocktail (Sigma-Aldrich; Merck KGaA). Protein concentration was determined with the DC $^{\text {TM }}$ Protein Assay system (Bio-Rad Laboratories), $50 \mu \mathrm{g}$ of protein were loaded on 10\% SDS-PAGE gel and electrophoretically transferred onto nitrocellulose membranes. After being blocked with 5\% nonfat powdered milk in Dulbecco phosphate-buffered saline, the membranes were incubated with $1 \mu \mathrm{g} / \mathrm{ml}$ of specific antibodies. The following antibodies were used: Polyclonal antibodies against CDK4 (C-22), $\beta$-actin (I-19) (Santa Cruz Biotechnology, Inc.), CENP-P (PA5-31186), and Aurora-B (MA5-17226) (Thermo Fisher Scientific Inc.; Pierce Biotechnology Inc.). Membranes were washed and incubated with goat anti-rabbit-HRP (sc-2004), donkey anti-goat-HRP, or goat anti-mouse-HRP secondary antibodies followed by enhanced chemiluminescence (ECL detection kit; GE Healthcare). Western blot bands were quantified using UN-SCAN-IT gel version 6.1 software. The experimental data are representative of three independent repetitions.

Chromatin immunoprecipitation (ChIP) assay. We utilized the SimpleChIP ${ }^{\circledR}$ Enzymatic chromatin IP kit (Cell Signaling Technology, Inc., MA) following the manufacturer's instructions. Briefly, $4 \times 10^{7}$ NIH3T3 semi-confluent cells were used for ChIP assay. Cell culture media was replaced with $10 \mathrm{ml}$ of fresh media containing $1 \%$ formaldehyde to crosslink proteins/DNA and incubated for $10 \mathrm{~min}$ at RT. The reaction was stopped by the addition of glycine, a $0.125 \mathrm{M}$ concentration in cell culture media. Cells were washed with PBS, scraped, collected into conical tubes, and centrifuged at 1,500 rpm. Chromatin was released by adding lysis buffer containing DTT, protease inhibitors, and PMSF and further fragmented by partial digestion with micrococcal nuclease to obtain chromatin fragments of 1 to 5 nucleosomes in size. Nuclei were 
pelleted by centrifugation at $13,000 \mathrm{rpm}$ and resuspended in $1 \mathrm{X}$ ChIP buffer containing SDS, protease inhibitor, and PMSF. Pellets were sonicated (3 sets of 20 -second pulses at setting 2 on a Branson sonifer 450) and clarified by centrifugation at 10,000 rpm for $10 \mathrm{~min}$. The supernatant was kept at $-80^{\circ} \mathrm{C} .50 \mu \mathrm{l}$ of chromatin sample were digested with $2 \mu \mathrm{l}$ RNase A at $37^{\circ} \mathrm{C}$ for $30 \mathrm{~min}$ and $2 \mu 1$ Proteinase $\mathrm{K}$ at $65^{\circ} \mathrm{C}$ for $2 \mathrm{~h}$. DNAs were purified using spin columns, and $10 \mu \mathrm{l}$ was used to electrophoresis on $1 \%$ agarose gel to check DNA fragment sizes. DNA concentration was determined with a NanoDrop 1000 (Thermo Fisher Scientific, Inc.). $10 \mu \mathrm{g}$ chromatin was diluted in $500 \mu \mathrm{l}$ of $1 \mathrm{X}$ ChIP buffer containing protease inhibitor cocktail and used for each immunoprecipitation. $2 \mu \mathrm{g}$ of rabbit antibodies against CDK4 (C-22) (Santa Cruz Biotechnology, Inc.), normal IgG (New England Biolabs) or Histone H3 (D2B12) (New England Biolabs) were added to DNA samples and incubated overnight at $4^{\circ} \mathrm{C}$. Thirty microliters of ChIP-grade protein $\mathrm{G}$ agarose beads (Cell Signaling Technology, Inc.) were added to each sample and incubated for $2 \mathrm{~h}$ at $4^{\circ} \mathrm{C}$, followed by centrifugation $6,000 \mathrm{rpm}$ for $1 \mathrm{~min}$. The supernatant was transferred to a new tube and processed for immunoprecipitation 3 times. The agarose pellet was washed with ChIP buffer three times and ChIP buffer with high salt $(350 \mathrm{mM} \mathrm{NaCl})$. Chromatin was eluted from antibody/protein $\mathrm{G}$ bead through incubations at $65^{\circ} \mathrm{C}, 30 \mathrm{~min}$ with gentle vortex, separated by centrifugation at 6,000 rpm, and transferred to a new tube. RNA and proteins in Eluted DNA were removed through RNase A and proteinase $\mathrm{K}$ treatment, and DNA was purified through the spin column, as mentioned above.

Standard PCR was performed using $50 \mathrm{ng}$ DNAs with specific primers for CENP-P, Aurkb, Ckap2, Zw10, Top2a, and Mlf1ip genes as previously reported (7) with KAPA2G Fast PCR kit (KAPA Biosystems). PCR was executed using 34 cycles of amplification: Denaturation at $95^{\circ} \mathrm{C}$ for $30 \mathrm{sec}$, annealing at $50^{\circ} \mathrm{C}$ (CENP-P, Aurkb), $56.8^{\circ} \mathrm{C}$ (Mlflip) and $62^{\circ} \mathrm{C}$ (Zw10, Top2a) for $30 \mathrm{sec}$, extension at $72^{\circ} \mathrm{C}$ for $30 \mathrm{sec}$, and a final extension at $72^{\circ} \mathrm{C}$ for $5 \mathrm{~min}$. PCR primers: CENP-P (CAT GGAGATCCGCAGTACC; CATCCCTTCCTCATCGATTT) Aurkb (CCCAGAGAGTCCTACGGAAG; TGTTCTCAGCCA ACTTCTGG) Ckap2 (ATTAAGCGATGGCAGAGTCC; TTT CTTTGTTCTCGGAAGGC) Zw10 (GAAGTGCCAGGATGT GATTG; AGCTTGTGATCAGCATCAGG) Top2A (ATCACC GACTCGCTCTCATT; GCACATGGACCTTCCTCATT).

Quantitative PCR ( $q R T-P C R)$. Synthesis of cDNA with total RNA was performed using an iScript cDNA synthesis kit (Bio-Rad Laboratories). Two micrograms of total RNA and reverse transcriptase $\mathrm{H}$ was incubated in reaction buffer $5 \mathrm{~min}$ at $25^{\circ} \mathrm{C}, 30 \mathrm{~min}$ at $42^{\circ} \mathrm{C}$, and $5 \mathrm{~min}$ at $85^{\circ} \mathrm{C}$. The iQTM SYBR ${ }^{\circledR}$-Green Supermix (Bio-Rad Laboratories) was used for quantitative real-time PCR. The same primers used for ChIP assays were utilized for this analysis, and mouse GAPDH as the reference gene. PCR amplification was performed with a $20 \mu \mathrm{l}$ reaction mixture containing $2 \mu \mathrm{l}$ of cDNA, $300 \mathrm{nM}$ of each primer, and 1x iQTM SYBR ${ }^{\circledR}$-Green supermix (Bio-Rad Laboratories). PCR condition as followed: Initial denaturation at $95^{\circ} \mathrm{C}$ for $3 \mathrm{~min}$, followed by 40 cycles of denaturation at $95^{\circ} \mathrm{C}$ for $15 \mathrm{sec}$, annealing, and extension at $60^{\circ} \mathrm{C}$ for $30 \mathrm{sec}$. The transcriptional level of target genes was normalized by the transcriptional level of GAPDH (CATCACTGCCAC CCAGAAGACTG; ATGCCAGTGAGCTTCCCGTTCAG). For downregulation assays, the transcriptional levels were compared with control siRNA-treated 308 cells or cell lines, not overexpressing CDK4 (NIH3T3 or 308) according to the algorithms 2-( $\Delta \Delta \mathrm{Ct})$, respectively.

siRNA assay. Cell lines were transfected with CDK4 or control siRNAs with Lipofectamine ${ }^{\circledR}$ RNAiMAX Reagent (Invitrogen, Life Technologies) according to the manufacturer's instructions. 308 or 308-CDK4 cells were cultured in $60 \mathrm{~mm}$ Petri dishes at $70-80 \%$ of confluence. We utilized commercially available CDK4 specific siRNA (sc-29262) and control siRNA (sc-37007) (Santa Cruz Biotech). Briefly, 60 pmol of siRNA was diluted in $300 \mu$ l Opti-MEM ${ }^{\circledR}$ (Invitrogen; Life Technologies),

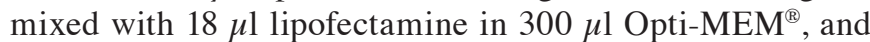
incubated $5 \mathrm{~min}$ at RT. The mixture was added to the cells in $4 \mathrm{ml}$ of culture media without antibiotics. The media was replaced with fresh media after $24 \mathrm{~h}$, and cells were harvested $96 \mathrm{~h}$ after the transfection. RNA was isolated using TRIzol ${ }^{\circledR}$ Reagent (Ambion, Life Technologies).

Statistical analysis. An unpaired Student's t-test was performed using GraphPad Prism 4 Software (GraphPad Software).

\section{Results}

CDK4 loaded onto the chromatin fraction of mouse keratinocytes. Various studies accomplished in the last decade have shown that cyclin D1 and CDK6 have additional functions non-related to their role in the cyclin-cdk-Rb axis (9-11). Based on these observations, we asked whether CDK4 has similar activities in transcriptional regulation (26). Thus, we first examined the CDK4 interaction with the chromatin fraction of mouse keratinocytes. We performed in situ cell extraction with the cytoskeleton extraction buffer (CSK), which removes the soluble proteins from the cytoplasm and nucleoplasm while leaving the chromatin-bound fraction intact (27-29). We utilized asynchronous cell cultures of primary mouse keratinocytes and the keratinocyte cell line 308, a cell line derived from BALB/c mouse skin treated with 7,12-dimethylbenz[a] anthracene $(21-23,30)$. Immunofluorescence analysis of the extracted cells revealed the presence of CDK4 in the chromatin-bound fraction of both mouse primary keratinocytes and 308 keratinocyte cell lines (Fig. 1A-L). The CSK extraction buffer removes the soluble cell fractions, but the DNA and other insoluble material such as intermediate filament cytoskeleton remain in the so-called cell ghosts. Therefore, to verifies that CDK4 binds to DNA, we disrupt the cellular DNA and examine the presence of CDK4 and the positive control chromatin-bound histone deacetylase 1 (HDAC1). DNase treatment released the DNA-bound HDAC1 and CDK4 from the chromatin fraction (Fig. 1M-R), confirming that CDK4 is strongly associated with the DNA fraction of mouse keratinocytes.

CDK4 as a transcriptional regulator on the Aurkb and $C E N P-P$ promoters. In addition to their well-established role in the cell cycle, cyclin D1 and CDK6 have transcriptional functions $(7,9,10)$. Whereas cyclin D1 plays a direct role in 

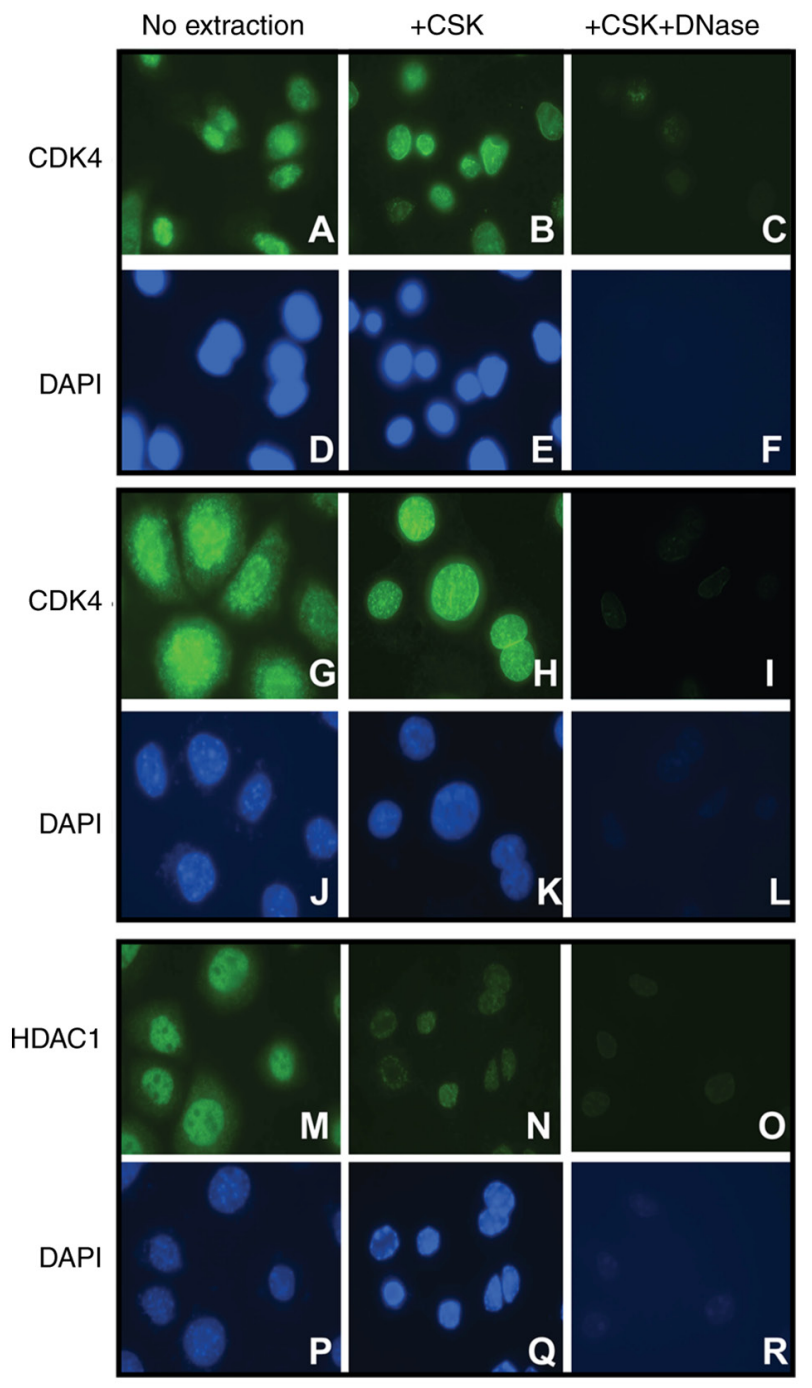

Figure 1. CDK4 interacts with the chromatin fraction of mouse keratinocytes Immunofluorescence analysis of CDK4 (green) in (A-C) primary mouse keratinocytes and the (G-I) mouse keratinocyte cell line 308 treated with cytoskeletal extraction buffer (+CSK) and cytoskeletal extraction buffer followed by DNase I (+CSK +DNase). DAPI was used as a nuclear counterstain (blue) for $(\mathrm{D}-\mathrm{F})$ primary mouse keratinocytes and $(\mathrm{J}-\mathrm{L})$ mouse keratinocyte cell line 308. (M-O) HDAC1 was used as a positive control of chromatin-bound proteins in the keratinocyte cell line 308, with (P-R) DAPI as a nuclear counterstain (blue). CDK4, cyclin-dependent kinase 4; CSK, cytoskeletal extraction buffer; HDAC1, histone deacetylase 1 .

transcriptional regulation of genes governing chromosomal integrity (7), CDK6 is part of a complex that controls the transcription of $\mathrm{p}^{\mathrm{Ink} 4}$ and the angiogenic factor VEGF-A (9). In view of the presence of the DNA-bound CDK4, its structural and functional similitudes with CDK6, and because cyclin D1 is one of the regulatory subunits of CDK4, we analyzed whether CDK4 may also act as a transcriptional regulator. We first examined a set of genes transcriptionally controlled by cyclin D1, which were previously reported that regulate chromosome segregation (7). Chromatin immunoprecipitation (ChIP) experiments revealed that CDK4 binds specifically to the Aurkb, CENP-P, and Zw10 promoters, while no binding to Ckap2, Top2a, and Mlf1ip was detected (Fig. 2A). These findings suggest that CDK4 may behave as a transcriptional regulator or form part of a transcriptional complex that controls genes associated with chromosomal segregation.
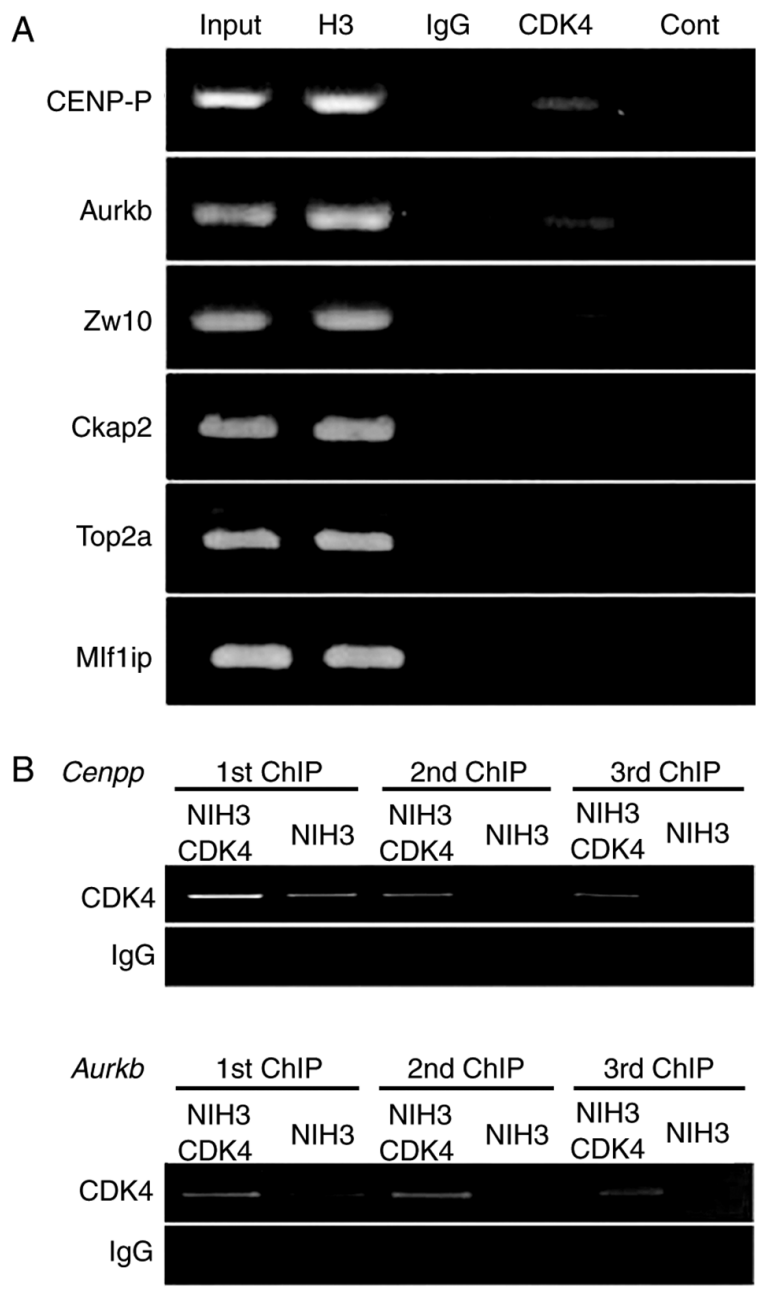

Figure 2. CDK4 binds to regulatory regions of genes associated with chromosomal segregation. (A) ChIP analysis of NIH3T3 cells performed with an anti-CDK4 antibody (CDK4). Chromatin input and ChIP with anti-H3 antibody were used as positive controls, and normal IgG was used as a negative control. 'Cont' indicated the blank of the PCR reaction. The binding of CDK4 to specific promoters was analyzed by standard PCR with primers that amplified the regulatory sequences CENP-P, Aurkb, Ckap2,Zw10, Top2a and Mlf1ip genes. (B) Increased binding to the regulatory regions of CENP-P and Aurkb genes upon overexpression of CDK4 in NIH3T3 cells (NIH3T3-CDK4). ChIP analysis of NIH3T3 and NIH3T3-CDK4 cells was performed in three sequential immunoprecipitations with an anti-CDK4 antibody. $\mathrm{H} 3$, Histone 3 ; CDK4, cyclin-dependent kinase 4; ChIP, chromatin immunoprecipitation; CENP-P, Centromere Protein P; Aurkb, Aurora-B; Ckap2, cytoskeleton-associated protein 2; Zw10, centromere/kinetochore protein zw10 homolog; Top2a, DNA topoisomerase 2-a; Mlf1ip, MLF1-interacting protein.

To delineate whether variation in the CDK4 protein level affects the interaction to the regulatory sites of these genes, we performed ChIP analysis of NIH3T3 cells overexpressing murine CDK4 (NIH3T3-CDK4). We carry out ChIP assay in three sequential immunoprecipitations and quantify the association of CDK4 with Aurkb and CENP-P promoters in NIH3T3-CDK4 cells and the parental cell line NIH3T3. CDK4 overexpressing cells showed a 3-, 5- and 9-fold increase binding to the CENP-P promoter in the three sequential immunoprecipitations, respectively, compared to NIH3T3 cells (Fig. 2B). Similarly, NIH3T3-CDK4 cells showed 2and 7-fold increase binding to Aurkb promoter in the first and second immunoprecipitation, respectively, compared to NIH3T3 cells (Fig. 2B). ChIP analysis of the Zw10 promoter 
showed no differences between CDK4 overexpressing and parental cell lines. These results support the specificity of CDK4 binding to Aurkb and CENP-P promoters and suggest that variation in the $\mathrm{CDK} 4$ level might affect the transcription of Aurkb and CENP-P genes.

To examine whether CDK4 regulates the transcription of these genes, we quantified the transcription of Aurkb B and CENP-P genes upon overexpression and downregulation of CDK4. We performed quantitative PCR (qRT-PCR) of CENP-P, Aurkb, Zw10, Ckap2, and Top2a on NIH3T3 cells and the keratinocyte cell line 308 overexpressing CDK4 (NIH3T3-CDK4, 308-CDK4) and the parental cells lines NIH3T3 and 308. The transcriptional levels were normalized to the Gapdh, and a transcriptional ratio calculated between CDK4 overexpressing and the parental cell lines. NIH3T3-CDK4 cells showed a 2-fold increase in transcription of Aurkb $(\mathrm{P}<0.005$, t-test $)$ and 1.5-fold elevate transcription of CENP-P $(\mathrm{P}<0.05$, $\mathrm{t}$-test $)$ compared to NIH3T3 cells. Similarly, we observed 3-(P<0.05, t-test $)$ and 2 -fold $(\mathrm{P}<0.005$, $\mathrm{t}$-test) elevated transcription of Aurkb and CENP-P, respectively, in the keratinocyte cell line 308-CDK4 (Fig. 3A). The enhanced expression of CDK4 did not significantly change the transcriptional levels of Ckap2 gene, although a 2- and 1.3-fold reduction of Zw10 (P<0.05, t-test) and Top2a $(\mathrm{P}<0.0005$, t-test) genes. Recently reports showed that Top2a and Zw10 proteins are involved in chromosome segregation and mitotic checkpoint proteins (31-35); therefore, their potential role downstream of CDK4 expression in cell proliferation and tumor development warrants further investigation. We also studied the protein levels of Aurora-B and CENP-P in both NIH3T3-CDK4 and 308-CDK4 cell lines. Increased protein levels of both CENP-P and Aurora-B were observed upon overexpression of CDK4 in the 308-cell line (Fig. 3B). 308-CDK4 cells showed a 20 -fold increase of CENP-P $(\mathrm{P}<0.05$, t-test $)$ and a 4-fold increase of Aurora-B $(\mathrm{P}<0.05$, $\mathrm{t}$-test $)$ compared to 308 cells. Expression of CENP-P protein was elevated 2 -fold $(\mathrm{P}<0.05$, t-test) in NIH3T3-CDK4 cells, although the protein level of Aurora-B showed a non-statistically significant change compared to NIH3T3 cells (Fig. 3B). Altogether, these results demonstrated that the CDK4 protein indeed regulates the transcription of Aurkb and CENP-P.

To validate our conclusions, we determined the effect of the reduction level of CDK4 on Aurkb and CENP-P transcription. We evaluated the inhibitory effect of CDK4-specific siRNA on the levels of Aurkb and CENP-P. The keratinocyte cell line 308 overexpressing CDK4 and the parental cell line 308 were transfected with CDK4-specific siRNA and a control scramble-siRNA. The transcription levels of Aurkb and CENP-P, normalized to the transcriptional level of Gapdh, were quantified by qRT-PCR and compared between CDK4-siRNA and control-siRNA transfected cells. We observed a reduction in Aurkb and CENP-P RNA levels in both 308-CDK4 and 308 cells $72 \mathrm{~h}$ after transfection with CDK4-siRNA (Fig. 4A). CDK4-siRNA lead to a $24 \%(\mathrm{P}=0.02)$ and $51 \%(\mathrm{P}=0.01)$ decrease of CENP-P RNA expression in 308 and 308-CDK4 cells respectively (Fig. 4A). Aurkb RNA levels were reduced by $46 \%(\mathrm{P}=0.01, \mathrm{t}$-test $)$ and $78 \%(\mathrm{P}=0.0005$, $\mathrm{t}$-test $)$ in 308 and 308-CDK4 cells respectively (Fig. 4A). The effect of CDK4-siRNA was monitored by Western blot analysis $72 \mathrm{~h}$ after transfection showing a 50- and 10-times reduction of CDK4, correlating with the 10 - and 2-fold decreased level of
A

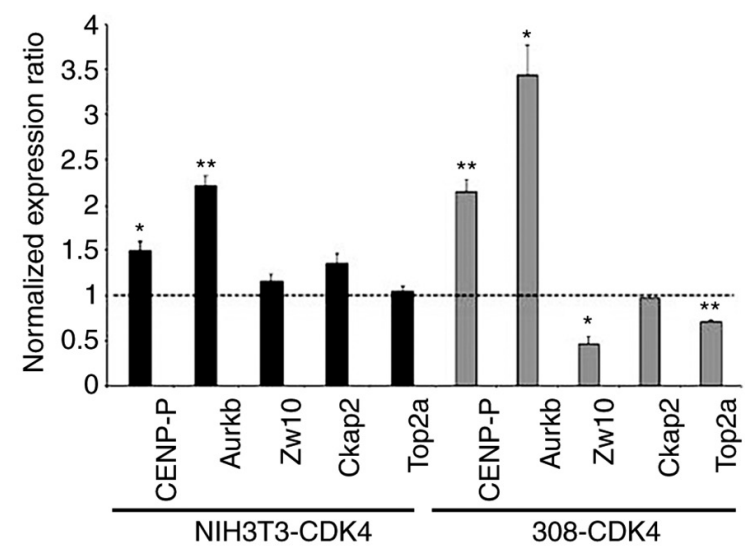

B

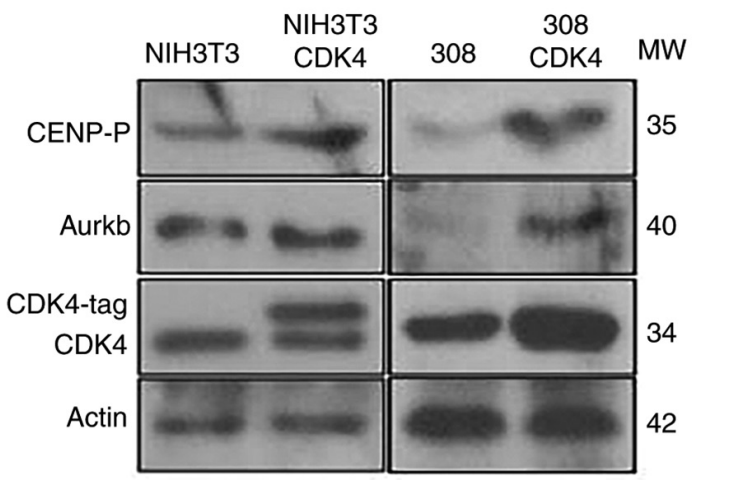

Figure 3. Transcription and protein expression levels of CENP-P and Aurkb are increased following overexpression of CDK4. (A) Transcriptional levels of CENP-P, Aurkb, Zw10, Ckap2 and Top2a were determined by reverse transcription-quantitative PCR analysis. Shown are normalized expression ratios of cells overexpressing CDK4 (NIH3T3-CDK4 and 308-CDK4) compared with parental cells (NIH3T3 and 308). Values $>1$ denote increased transcriptional expression in CDK4 overexpressing cells, whereas values $<1$ denote reduced or equal transcription levels compared with parental cell lines. All the results were normalized with Gapdh expression. $n=3$ independent experiments, data are presented as the mean \pm SEM. Student's t-test was performed. ${ }^{*} \mathrm{P}<0.05,{ }^{* *} \mathrm{P}<0.005$ vs. appropriate parental cell line. (B) Western blot analysis of CENP-P, Aurkb and CDK4 in cells overexpressing CDK4 (NIH-CDK4, 308-CDK4) and the control cell lines infected with control retrovirus (NIH3T3, 308). $\beta$-Actin was used as a loading control. CDK4, cyclin-dependent kinase 4; CENP-P, Centromere Protein P; Aurkb, Aurora-B; Ckap2, cytoskeleton-associated protein 2; Zw10, centromere/kinetochore protein zw10 homolog; Top2a, DNA topoisomerase 2; MW, molecular weight.

Aurora-B protein in 308 and 308-CDK4 cells, respectively (Fig. 4B). Taken together, these analyses revealed that the binding of CDK4 to the regulatory site of Aurkb and CENP-P genes leads to positive transcriptional regulation.

\section{Discussion}

The canonical role of CDK4 and D-type cyclins as drivers of cell proliferation and tumorigenesis via phosphorylation of the retinoblastoma $(\mathrm{Rb})$ family of proteins has been firmly established. However, over the last few years, it has been suggested that CDK4 plays alternative functions in proliferation and tumorigenesis (8). For example, CDK4 can also phosphorylate the transcription factor FOXM1, which in turn induces the transcription of other genes involved in the G2/M phases (12). Likewise, additional functions have been identified in different cell cycle regulators. For instance, the CDK4-related kinase, CDK6, performs transcriptional functions regulating the 



Figure 4. Transcription and protein expression levels of CENP-P and Aurkb are reduced following the knockdown of CDK4. (A) The transcriptional levels of CENP-P and Aurkb were determined by reverse transcription-quantitative PCR analysis in 308 cells overexpressing CDK4 (308-K4) and the parental cell line (308) $72 \mathrm{~h}$ after transfection with CDK4-specific siRNA (K4-siRNA) or control scramble-siRNA (Cont). Transcriptional levels were normalized with Gapdh expression. Three independent experiments were performed The data are presented as the mean \pm SD. Student's t-test was performed ${ }^{*} \mathrm{P}<0.01,{ }^{* *} \mathrm{P}<0.002,{ }^{* * *} \mathrm{P}<0.0005$. (B) Representative western blot analysis of Aurkb and CDK4 expression $72 \mathrm{~h}$ post-transfection with CDK4-siRNA specific (K4-siRNA) or control scramble-siRNA (siRNA) of 308 cells overexpressing CDK4 (308-K4) and the parental cell line (308). $\beta$-actin was used as a loading control. CDK4, cyclin-dependent kinase 4; CENP-P, Centromere Protein P; Aurkb, Aurora-B; siRNA, small interfering RNA.

expression of VEGF-A and p16 ${ }^{\mathrm{INK} 4 \mathrm{a}}(9)$. Cyclin D1, a regulatory subunit of CDK4 and CDK6, participates in activities other than cell-cycle regulation, such as interaction with the androgen and estrogen receptors and DNA repair $(8,10,11)$.

Notably, it was recently reported a transcriptional role of cyclin D1 regulating chromosome segregation genes such as Aurkb, CENP-P, Zw10, Ckap2, Top2a and Mlf1ip (7). Our present findings indicate that CDK4 also regulates the transcription of Aurkb and CENP-P, two genes involved in chromosome segregation. Aurora B expression has a key role in chromosome bi-orientation and spindle-assembly checkpoint, whereas Cenpp is required for proper kinetochore function $(19,20,36)$. Our studies have also established a major difference between the transcriptional activities of CDK4 and cyclin D1 (7). Both CDK4 and cyclin D1 localizes on the regulatory sites of Aurkb, CENP-P, and Zw10 genes, but only cyclin D1 bind to Ckap2, Top2a, and Mlf1ip promoters (7). These results led us to hypothesize that CDK4 and cyclin D1 may act as a complex at the regulatory sites of Aurkb and CENP-P genes, whereas cyclin D1 may act independently of CDK4 in other contexts. Interestingly, the CDK4 binding to the Zw10 promoter does not result in changes in the transcription level of this gene. It is worth mentioning that the transcriptional role of cyclin D1 was determined in $\mathrm{Ccnd}^{-/-}$mouse embryo fibroblasts (MEF) transfected with an epitope-tagged cyclin D1. In contrast, we studied the effect of CDK4 gain- and lost-of-function in keratinocytes and embryo fibroblast cell lines. Therefore, whether the differences observed in the transcription of Ckap2, Top2a, Mlf1ip, and Zw10 genes represent cell-specific regulation or technical discrepancies between these experiments merit further analysis.

Notably, it has been suggested that CDK4 activity is necessary for regulation of phase others than $\mathrm{G}_{0}$ and $\mathrm{G}_{1}(8,37)$. Inhibition of CDK4 activity results in delayed progression from $\mathrm{G}_{2}$ to mitosis due to a failure of chromosomes to migrate to the metaphase plate, implying that CDK4 is necessary for entry into mitosis $(38,39)$. Consistent with these findings, our studies also showed that the transcriptional and protein levels of Aurkb and CENP-P correlate well with CDK4 expression. Notably, Aurora-B mRNA and protein levels are tightly regulated and peak at the $\mathrm{G}_{2}-\mathrm{M}$ phases $(40,41)$, correlating well with the putative activity of CDK4 in the $\mathrm{G}_{2} / \mathrm{M}$ phase. Although the mechanisms regulated by CDK4 in the $\mathrm{G}_{2}-\mathrm{M}$ phase have not been clearly defined, it is known that CDK4 inhibition reduces mitosis's fidelity, implying that CDK4 indeed takes part in the $\mathrm{G}_{2} / \mathrm{M}$ phase by regulating Aurora B (38).

Given that CDK4 inhibitors are in active clinical development (42-45), it is crucial to understand the role of CDK4 regulating Aurkb and CENP-P in tumor development. In this regard, we demonstrated that transgenic expression of CDK4 induces keratinocyte proliferation and accelerates the malignant progression of mouse skin tumors (13-15). In contrast, lack of CDK4 expression inhibits skin and oral tumor development $(46,47)$. We have also determined that CDK4, but not the related kinases CDK6 and CDK2, induce skin tumor malignant progression (13-15). Thus, the effect of CDK4 inducing tumor progression might be related to its role in the transcriptional activity of Aurkb and CENP-P. Aurora-B is a subunit of the chromosomal passenger complex (CPC) controlling chromosome segregation $(41,48,49)$ and potentially contribute to the Spindle-Assembly-Checkpoint (SAC), which malfunction leads to aneuploidy and tumorigenesis (18). In fact, long-term overexpression of Aurora-B in vivo results in defective chromosome segregation, aneuploidy, and the development of multiple tumors in mice (50-54). Similarly, CENP-P is a subunit of the centromeric complex required for proper kinetochore function contributing to chromosome segregation (20). Thus, the potential effect of CDK4 dysregulation in Aurkb and CENP-P expression leading to CIN and tumorigenesis warrant further investigation.

Studies demonstrating that inactivation of CDK4 and D-type cyclins can prevent tumor development in murine models reinforced the view that CDK4 is suitable for cancer-specific targets $(46,47,55,56)$. Based on these results, in the last decade, CDK inhibitors were designed, which are in clinical development or have already been approved by the US Food and Drug Administration (42-45,57-59). For example, the observed preclinical and clinical effects of palbociclib are consistent with the notion that inhibition of CDK4/6 is a crucial mechanism underlying tumor growth activity (60-63). However, some of these drugs have been met with variable degrees of success in preclinical and clinical studies. Thus, the CDK4 binding to the promoter regions should be confirmed with assays in which specific CDK4-inhibitors, such as Abemaciclib and Palbociclib, are administered to keratinocytes. Those experiments will be fundamentals to determine 
the effect of the CDK4 kinase activity in the transcriptional role of CDK4. If the function of CDK4 regulating Aurkb and CENP-P levels is not inhibited by the current drugs, then this new activity might represent an important therapeutic target to disrupt cell cycle progression in cancer cells. Such a scenario could help to explain the reduced efficacy of the existing CDK4 drugs in some cancers and open new research avenues for future studies directed to provide new CDK4-related targets for combined therapeutic interventions.

\section{Acknowledgements}

The authors would like to thank the Laboratory Animal Resources and the Histology Core at the College of Veterinary Medicine, North Carolina State University (Raleigh, USA) for helping with the processing and staining of skin samples.

\section{Funding}

Research reported in this publication was supported by grants from the National Cancer Institute (grant no. RO1CA116328) and the National Institute of Environmental Health Sciences (grant no. P30ES025128; Center for Human Health and the Environment).

\section{Availability of data and materials}

The datasets used and/or analyzed during the current study are available from the corresponding author on reasonable request.

\section{Authors' contributions}

MLRP was responsible for the design and conception of the experiments, and was the guarantor of this work and, as such, takes responsibility for the integrity of the data and the accuracy of the data analysis. SHL carried out the experiments and contributed to data analysis and interpretation. LRLR and PLMDM conceived and designed part of the experiments, and wrote part of the results section. RM designed the primers utilized in part of this paper, and performed the immunofluorescence staining and semi-quantification of the western blots. All authors provided critical feedback and helped shape the research, analysis and manuscript. SHL and MLRP wrote the manuscript and confirm the authenticity of all the raw data. All authors have read and approved the final manuscript.

\section{Ethics approval and consent to participate}

The generation of mouse primary keratinocytes and protocols for animal use were approved by the Institutional Animal Care and Use Committee of North Carolina State University (approval no. 18-102-B; Raleigh, USA).

\section{Patient consent for publication}

Not applicable.

\section{Competing interests}

The authors declare that they have no competing interests.

\section{References}

1. Fischer PM, Endicott J and Meijer L: Cyclin-dependent kinase inhibitors. Prog Cell Cycle Res 5: 235-248, 2003.

2. Lukasik P, Zaluski M and Gutowska I: Cyclin-dependent kinases $(\mathrm{CDK})$ and their role in diseases development-review. Int J Mol Sci 22: 2935, 2021

3. Suryadinata R, Sadowski M and Sarcevic B: Control of cell cycle progression by phosphorylation of cyclin-dependent kinase (CDK) substrates. Biosci Rep 30: 243-255, 2010.

4. Gitig DM and Koff A: Cdk pathway: Cyclin-dependent kinases and cyclin-dependent kinase inhibitors. Methods Mol Biol 142: 109-123, 2000.

5. Weinberg RA: The molecular basis of carcinogenesis: Understanding the cell cycle clock. Cytokines Mol Ther 2: 105-110, 1996.

6. Ewen ME, Sluss HK, Sherr CJ, Matsushime H, Kato J and Livingston DM: Functional interactions of the retinoblastoma protein with mammalian D-type cyclins. Cell 73: 487-497, 1993.

7. Casimiro MC, Crosariol M, Loro E, Ertel A, Yu Z, Dampier W, Saria EA, Papanikolaou A, Stanek TJ, Li Z, et al: ChIP sequencing of cyclin D1 reveals a transcriptional role in chromosomal instability in mice. J Clin Invest 122: 833-843, 2012.

8. Hydbring P, Malumbres M and Sicinski P: Non-canonical functions of cell cycle cyclins and cyclin-dependent kinases. Nat Rev Mol Cell Biol 17: 280-292, 2016.

9. Kollmann K, Heller G, Schneckenleithner C, Warsch W, Scheicher R, Ott RG, Schäfer M, Fajmann S, Schlederer M, Schiefer AI, et al: A Kinase-Independent function of CDK6 links the cell cycle to tumor angiogenesis. Cancer Cell 24: 167-181, 2013.

10. Bienvenu F, Jirawatnotai S, Elias JE, Meyer CA, Mizeracka K, Marson A, Frampton GM, Cole MF, Odom DT, Odajima J, et al: Transcriptional role of cyclin D1 in development revealed by a genetic-proteomic screen. Nature 463: 374-378, 2010.

11. Jirawatnotai S,Hu Y,Michowski W, Elias JE, Becks L, Bienvenu F, Zagozdzon A, Goswami T, Wang YE, Clark AB, et al: A function for cyclin D1 in DNA repair uncovered by protein interactome analyses in human cancers. Nature 474: 230-234, 2011.

12. Anders L, Ke N, Hydbring P, Choi YJ, Widlund HR, Chick JM, Zhai H, Vidal M, Gygi SP, Braun P and Sicinski P: A systematic screen for CDK4/6 substrates links FOXM1 phosphorylation to senescence suppression in cancer cells. Cancer Cell 20: 620-634, 2011.

13. Miliani de Marval PL, Macias E, Conti CJ and RodriguezPuebla ML: Enhanced malignant tumorigenesis in Cdk4 transgenic mice. Oncogene 23: 1863-1873, 2004.

14. Macias E, Miliani de Marval PL, De Siervi A, Conti CJ, Senderowicz AM and Rodriguez-Puebla ML: CDK2 activation in mouse epidermis induces keratinocyte proliferation but does not affect skin tumor development. Am J Pathol 173: 526-535, 2008.

15. Wang X, Sistrunk C and Rodriguez-Puebla ML: Unexpected reduction of skin tumorigenesis on expression of cyclin-dependent kinase 6 in mouse epidermis. Am J Pathol 178: 345-354, 2011.

16. Adon AM, Zeng X, Harrison MK, Sannem S, Kiyokawa H, Kaldis P and Saavedra HI: Cdk2 and Cdk4 regulate the centrosome cycle and are critical mediators of centrosome amplification in p53-null cells. Mol Cell Biol 30: 694-710, 2010.

17. Carmena M, Wheelock M, Funabiki H and Earnshaw WC: The chromosomal passenger complex (CPC): From easy rider to the godfather of mitosis. Nat Rev Mol Cell Biol 13: 789-803, 2012.

18. Musacchio A and Salmon ED: The spindle-assembly checkpoint in space and time. Nat Rev Mol Cell Biol 8: 379-393, 2007.

19. Peters AH, Kubicek S, Mechtler K, O'Sullivan RJ, Derijck AA, Perez-Burgos L, Kohlmaier A, Opravil S, Tachibana M, Shinkai Y, et al: Partitioning and plasticity of repressive histone methylation states in mammalian chromatin. Mol Cell 12: 1577-1589, 2003.

20. D'Avino PP and Capalbo L: New auroras on the roles of the chromosomal passenger complex in cytokinesis: Implications for cancer therapies. Front Oncol 5: 221, 2015.

21. Strickland JE, Greenhalgh DA, Koceva-Chyla A, Hennings H, Restrepo C, Balaschak M and Yuspa SH: Development of murine epidermal cell lines which contain an activated rasHa oncogene and form papillomas in skin grafts on athymic nude mouse hosts. Cancer Res 48: 165-169, 1988. 
22. Hennings H, Michael D, Lichti U and Yuspa SH: Response of carcinogen-altered mouse epidermal cells to phorbol ester tumor promoters and calcium. J Invest Dermatol 88: 60-65, 1987.

23. Yuspa SH and Morgan DL: Mouse skin cells resistant to terminal differentiation associated with initiation of carcinogenesis. Nature 293: 72-74, 1981.

24. Lichti U, Anders J and Yuspa SH: Isolation and short-term culture of primary keratinocytes, hair follicle populations and dermal cells from newborn mice and keratinocytes from adult mice for in vitro analysis and for grafting to immunodeficient mice. Nat Protoc 3: 799-810, 2008.

25. Miliani de Marval PL, Kim SH and Rodriguez-Puebla ML: Isolation and characterization of a stem cell side-population from mouse hair follicles. Methods Mol Biol 1195: 259-268, 2014.

26. Kitagawa $\mathrm{M}$ and Lee SH: The chromosomal passenger complex (CPC) as a key orchestrator of orderly mitotic exit and cytokinesis. Front Cell Dev Biol 3: 14, 2015.

27. Madine MA, Swietlik M, Pelizon C, Romanowski P, Mills AD and Laskey RA: The roles of the MCM, ORC, and Cdc6 proteins in determining the replication competence of chromatin in quiescent cells. J Struct Biol 129: 198-210, 2000.

28. Martini E, Roche DM, Marheineke K, Verreault A and Almouzni G: Recruitment of phosphorylated chromatin assembly factor 1 to chromatin after UV irradiation of human cells. J Cell Biol 143: 563-575, 1998.

29. Geng Y, Whoriskey W, Park MY, Bronson RT, Medema RH, Li T, Weinberg RA and Sicinski P: Rescue of cyclin D1 deficiency by knockin cyclin E. Cell 97: 767-777, 1999.

30. Hennings H, Robinson VA, Michael DM, Petit GR, Jung R and Yuspa SH: Development of an in vitro analogue of initiated mouse epidermis to study tumor promoters and antipromoters. Cancer Res 50: 4794-4800, 1990.

31. Li HN, Zheng WH, Du YY, Wang G, Dong ML, Yang ZF and Li XR: ZW10 interacting kinetochore protein may serve as a prognostic biomarker for human breast cancer: An integrated bioinformatics analysis. Oncol Lett 19: 2163-2174, 2020.

32. Pauleau AL, Bergner A, Kajtez J and Erhardt S: The checkpoint protein Zw10 connects CAL1-dependent CENP-A centromeric loading and mitosis duration in Drosophila cells. PLoS Genet 15: e1008380, 2019

33. Park Y, Kim JS and Oh JS: Zw10 is a spindle assembly checkpoint protein that regulates meiotic maturation in mouse oocytes Histochem Cell Biol 152: 207-215, 2019.

34. Leonard J, Sen N, Torres R, Sutani T, Jarmuz A, Shirahige K and Aragón L: Condensin relocalization from centromeres to chromosome arms promotes Top2 recruitment during anaphase. Cell Rep 13: 2336-2344, 2015.

35. Bermejo R, Capra T, Gonzalez-Huici V, Fachinetti D, Cocito A, Natoli G, Katou Y, Mori H, Kurokawa K, Shirahige K and Foiani M: Genome-organizing factors Top2 and Hmol prevent chromosome fragility at sites of S phase transcription. Cell 138: 870-884, 2009.

36. Gruneberg U, Neef R, Honda R, Nigg EA and Barr FA: Relocation of Aurora B from centromeres to the central spindle at the metaphase to anaphase transition requires MKlp2. J Cell Biol 166: 167-172, 2004

37. Neuman E, Ladha MH, Lin N, Upton TM, Miller SJ, DiRenzo J, Pestell RG, Hinds PW, Dowdy SF, Brown M and Ewen ME: Cyclin D1 stimulation of estrogen receptor transcriptional activity independent of cdk4. Mol Cell Biol 17: 5338-5347, 1997.

38. Burgess A, Wigan M, Giles N, Depinto W, Gillespie P, Stevens F and Gabrielli B: Inhibition of S/G2 phase CDK4 reduces mitotic fidelity. J Biol Chem 281: 9987-9995, 2006.

39. Gabrielli BG, Sarcevic B, Sinnamon J, Walker G, Castellano M, Wang XQ and Ellem KA: A cyclin D-Cdk4 activity required for $\mathrm{G} 2$ phase cell cycle progression is inhibited in ultraviolet radiation-induced G2 phase delay. J Biol Chem 274: 13961-13969, 1999.

40. Kimura M, Uchida C, Takano Y, Kitagawa M and Okano Y: Cell cycle-dependent regulation of the human aurora $\mathrm{B}$ promoter. Biochem Biophys Res Commun 316: 930-936, 2004

41. Kimura M, Kotani S, Hattori T, Sumi N, Yoshioka T, Todokoro K and kano Y: Cell cycle-dependent expression and spindle pole localization of a novel human protein kinase, Aik, related to Aurora of Drosophila and yeast Ipl1. J Biol Chem 272: 13766-13771, 1997.

42. Fry DW, Harvey PJ, Keller PR, Elliott WL, Meade M, Trachet E, Albassam M, Zheng X, Leopold WR, Pryer NK and Toogood PL: Specific inhibition of cyclin-dependent kinase 4/6 by PD 0332991 and associated antitumor activity in human tumor xenografts. Mol Cancer Ther 3: 1427-1438, 2004.
43. Toogood PL, Harvey PJ, Repine JT, Sheehan DJ, VanderWel SN, Zhou H, Keller PR, McNamara DJ, Sherry D, Zhu T, et al: Discovery of a potent and selective inhibitor of cyclin-dependent kinase 4/6. J Med Chem 48: 2388-2406, 2005.

44. Infante JR, Cassier PA, Gerecitano JF, Witteveen PO, Chugh R, Ribrag V, Chakraborty A, Matano A, Dobson JR, Crystal AS, et al: A Phase I study of the cyclin-dependent kinase 4/6 inhibitor ribociclib (LEE011) in patients with advanced solid tumors and lymphomas. Clin Cancer Res 22: 5696-5705, 2016.

45. Patnaik A, Rosen LS, Tolaney SM, Tolcher AW, Goldman JW, Gandhi L, Papadopoulos KP, Beeram M, Rasco DW, Hilton JF, et al: Efficacy and safety of abemaciclib, an inhibitor of CDK4 and CDK6, for patients with breast cancer, non-small cell lung cancer, and other solid tumors. Cancer Discov 6: 740-753, 2016.

46. Rodriguez-Puebla ML, Miliani de Marval PL, LaCava M, Moons DS, Kiyokawa H and Conti CJ: Cdk4 deficiency inhibits skin tumor development but does not affect normal keratinocyte proliferation. Am J Pathol 161: 405-411, 2002.

47. Miliani de Marval PL, Macias E, Rounbehler R, Sicinski P, Kiyokawa H, Johnson DG, Conti CJ and Rodriguez-Puebla ML: Lack of cyclin-dependent kinase 4 inhibits c-myc tumorigenic activities in epithelial tissues. Mol Cell Biol 24: 7538-7547, 2004.

48. Glover DM, Leibowitz MH, McLean DA and Parry H: Mutations in aurora prevent centrosome separation leading to the formation of monopolar spindles. Cell 81: 95-105, 1995.

49. Gopalan G, Chan CS and Donovan PJ: A novel mammalian, mitotic spindle-associated kinase is related to yeast and fly chromosome segregation regulators. J Cell Biol 138: 643-656, 1997.

50. Gonzalez-Loyola A, Fernandez-Miranda G, Trakala M, Partida D, Samejima K, Ogawa H, Cañamero M, de Martino A, Martínez-Ramírez Á, de Cárcer G, et al: Aurora B overexpression causes aneuploidy and p21Cip1 repression during tumor development. Mol Cell Biol 35: 3566-3578, 2015.

51. Nguyen HG, Makitalo M, Yang D, Chinnappan D, St Hilaire C and Ravid K: Deregulated Aurora-B induced tetraploidy promotes tumorigenesis. FASEB J 23: 2741-2748, 2009.

52. Nguyen HG and Ravid K: Tetraploidy/aneuploidy and stem cells in cancer promotion: The role of chromosome passenger proteins. J Cell Physiol 208: 12-22, 2006.

53. Giet R, Petretti $C$ and Prigent C: Aurora kinases, aneuploidy and cancer, a coincidence or a real link? Trends Cell Biol 15: 241-250, 2005.

54. Katayama H, Brinkley WR and Sen S: The Aurora kinases: Role in cell transformation and tumorigenesis. Cancer Metastasis Rev 22: 451-464, 2003.

55. Yu Q, Geng Y and Sicinski P: Specific protection against breast cancers by cyclin D1 ablation. Nature 411: 1017-1021, 2001.

56. Yu Q, Sicinska E, Geng Y, Ahnström M, Zagozdzon A, Kong Y, Gardner H, Kiyokawa H, Harris LN, Stål O and Sicinski P: Requirement for CDK4 kinase function in breast cancer. Cancer Cell 9: 23-32, 2006.

57. Finn RS, Martin M, Rugo HS, Jones S, Im SA, Gelmon K, Harbeck N, Lipatov ON, Walshe JM, Moulder S, et al: Palbociclib and letrozole in advanced breast cancer. N Engl J Med 375: 1925-1936, 2016.

58. Long F, He Y, Fu H, Li Y, Bao X, Wang Q, Wang Y, Xie C and Lou L: Preclinical characterization of SHR6390, a novel CDK 4/6 inhibitor, in vitro and in human tumor xenograft models. Cancer Sci 110: 1420-1430, 2019.

59. Bisi JE, Sorrentino JA, Jordan JL, Darr DD, Roberts PJ, Tavares FX and Strum JC: Preclinical development of G1T38: A novel, potent and selective inhibitor of cyclin dependent kinases $4 / 6$ for use as an oral antineoplastic in patients with CDK4/6 sensitive tumors. Oncotarget 8: 42343-42358, 2017.

60. Dean JL, Thangavel C, McClendon AK, Reed CA and Knudsen ES: Therapeutic CDK4/6 inhibition in breast cancer: Key mechanisms of response and failure. Oncogene 29: 4018-4032, 2010.

61. Dean JL, McClendon AK, Hickey TE, Butler LM, Tilley WD, Witkiewicz AK and Knudsen ES: Therapeutic response to CDK4/6 inhibition in breast cancer defined by ex vivo analyses of human tumors. Cell Cycle 11: 2756-2761, 2012.

62. Schwartz GK, LoRusso PM, Dickson MA, Randolph SS, Shaik MN, Wilner KD, Courtney R and O'Dwyer PJ: Phase I study of PD 0332991, a cyclin-dependent kinase inhibitor, administered in 3-week cycles (Schedule 2/1). Br J Cancer 104: 1862-1868, 2011.

63. Zhang YX,SicinskaE,CzaplinskiJT,RemillardSP,MossS, Wang Y, Brain C, Loo A, Snyder EL, Demetri GD, et al: Antiproliferative effects of CDK4/6 inhibition in CDK4-amplified human liposarcoma in vitro and in vivo. Mol Cancer Ther 13: 2184-2193, 2014.

This work is licensed under a Creative Commons Attribution-NonCommercial-NoDerivatives 4.0 International (CC BY-NC-ND 4.0) License. 